\title{
Analysis of CSRR Based Circular Patch Monopole Antenna for Ku-band Satellite Communication Applications, C-band and X-band Applications
}

\author{
K. Teja Babu ${ }^{1, *}$, K.Ch. Sri Kavya ${ }^{2, \dagger}$, Sarat K. Kotamraju ${ }^{3, \ddagger}$, G.B.G. Tilak ${ }^{1 \S}$ \\ ${ }^{1}$ Research Scholar, Dept. of ECE, Koneru Lakshmaiah Education Foundation (Deemed to be University), Green \\ Fields, Vaddeswaram, Guntur-522502, Andhra Pradesh, India \\ 2 Professor, Dept. of ECE, Koneru Lakshmaiah Education Foundation (Deemed to be University), Green Fields, \\ Vaddeswaram, Guntur-522502, Andhra Pradesh, India \\ ${ }^{3}$ Professor \& Dean Skill Development, Dept. of ECE, Koneru Lakshmaiah Education Foundation (Deemed to be \\ University) Green Fields, Vaddeswaram, Guntur-522502, Andhra Pradesh, India
}

(Received 08 January 2021; revised manuscript received 16 February 2021; published online 25 February 2021)

\begin{abstract}
In this paper, a circular patch monopole antenna with circular CSRR slots is presented for WiMAX applications. The proposed antenna contains circular polarized patch with circular CSRR slots. Smaller triple-band antenna is planned by drawing CSRR slots on the radiating component. It is seen from the outcomes that the proposed antenna can be utilized for satellite communication application. In order to verify high separation between adjacent components, the circular patch monopole antenna array of the proposed antenna element is also manufactured and tested in order to make the proposed antenna a possible candidate to be incorporated into satellite communications. Utilizing this strategy, a changed circular monopole are proposed and examined as the plan model. Both estimated and reproduced results are given and talked about to confirming the legitimacy of proposed plan procedure. In an ordinary lab climate, the injurious multi-way transmission impacts on the exchange capacity of the model receiving wire pair were noticed and talked about. This streamlining procedure would not carry any size or cost increment to the printed monopoles, and the improvement of transmission execution is very detectable, which has all the earmarks of being a critical improvement over printed UWB monopoles.The antenna delivers maximum peak gain of $8.27 \mathrm{~dB}$ at $13.9 \mathrm{GHz}$. The proposed antenna with the dimensions of $26 \times 23 \times 1.6$. The estimated results: radiation pattern, peak gain, radiation efficiency is showing the good results. The proposed antenna can be utilized for C-band (4.2, 7.6 GHz), 5.5 (HYPERLAN) X-band (9.7 and 11.4 GHz) and $\mathrm{Ku}$-band $(13.9 \mathrm{GHz})$ satellite communication applications.
\end{abstract}

Keywords: Monopole antenna, High Gain, CSRR.

DOI: 10.21272/jnep.13(1).01016

PACS number: 84.40.Ba

\section{INTRODUCTION}

For the huge demand and necessity of low power devices such as embedded devices in the present situation and industrial use, there is a need for substantial research to increase the power requirements of these devices. By using electromagnetic spectrum, it can be convinced to incorporate RF energy harvesting. Thus, it is necessary to reduce the maintenance part and the production cost from the device point of view [1]. Among the different antenna architectures, the micro strip ultra-wideband (UWB) monopole antenna draws design and developers' interest because these micro strip antennas can be conveniently operating over the entire UWB spectrum starting from 3.1 to $10.6 \mathrm{GHz}$. When no intervening signal occurs in the area, these antennas can use the full UWB spectrum. In comparison, current narrowband networks, such as Wireless Local Area Network WLAN (from $5.15 \mathrm{GHz}$ to $5.35 \mathrm{GHz}$ and from $5.725 \mathrm{GHz}$ to $5.825 \mathrm{GHz}$ ), Worldwide interoperability for Microwave Access WiMAX (from $3.3 \mathrm{GHz}$ to $3.6 \mathrm{GHz}$ ), High Performance Radio LAN HIPERLAN (from $5.45 \mathrm{GHz}$ to $5.725 \mathrm{GHz}$ ) and International Telecommunication Union ITU (from $8.02 \mathrm{GHz}$ to $8.4 \mathrm{GHz}$ ), could be influenced by the wide frequency spectrum of the UWB system [2]. During years of research, several methods to produce circular polarization have been suggested. A lightweight CP antenna has been suggested with the help of Meta materials such as meta-surfaces and meta-resonators. The proposed antenna has a gain of $4.15 \mathrm{~dB}$ while the antenna operates at narrowband frequencies. The proposed antenna achieved the circular polarization with the help of multiple feed structures and circular polarization bandwidth is 1.05 percent which is 40 percent bandwidth [3]. The low-profile and miniatured characteristics of the micro strip antennas minimize those structures. Antenna features such as wide operating bandwidth, (20) high gain in the desired direction, high axial ratio bandwidth, low-cost to fabricate, simple geometrical structure, and simple feeding techniques are chosen for many number of applications for improved reception of electromagnetic waves from a design point of view. The proposed micro strip patch antenna in $[4,5]$ has a large impedance bandwidth in the planner framework, but the antenna has low gain. In order to increase micro strip antenna gain [6-8], the placement of antennas in sequential order with equal spacing called antenna array technique and meta-materials are used [9]. The broadband high gain antenna reported in

\footnotetext{
*tejakolusu1@gmail.com

$\dagger$ kavya@kluniversity.in

$\ddagger$ kksarat@kluniversity.in

§ pbalagangadhar@kluniversity.in
} 
[10-12] is designed to produce linearly polarized waves from metals with large bandwidth and gain. Two kinds of feeding strategies used to produce circular polarization are using parasitic patch with single feed structure and another one is dual-feed technique [13]. There is a rising interest recently in the development of the single-fed operating at dual-band [14] with dual-sense circular polarized micro strip antennas. An analysis of the literature shows that researchers have spent significant effort in applying diverse strategies for the realization of circularly polarized (CP) antennas [15], both wideband and compact. However, maintaining the miniaturization of components of wireless devices, an antenna operating at dual band of frequencies or operating at multiband of frequencies is more important than a wideband antenna. A micro strip patch antenna fed with micro strip feed line or coplanar waveguide (CPW) are common choice for researchers to overcome those problems [16-19].

In this paper, a circular patch monopole antenna having inverted CSRR slots is demonstrated for WiMAX applications. The proposed circular patch antenna contains circular polarized patch with circular CSRR slots. Smaller triple-band antenna is planned by drawing CSRR slots on the radiating component. It is seen from the outcomes that the proposed circular patch antenna is best suitable for WiMAX, C-band applications, X-band applications and $\mathrm{Ku}$-band satellite communication applications.

\section{UNIT CELL ANALYSIS}

Fig. 1 outlines the unit cell structure. Its plan boundaries were $\mathrm{LP}=12.6 \mathrm{~mm}, \mathrm{WP}=12.6 \mathrm{~mm}$. The AMC unit cell in the inset is illuminated by an upper and lower floquet port bordered by Splitters for PEC and PMC. The simulated reflection characteristics of an AMC unit cell is selected for the designed antenna is

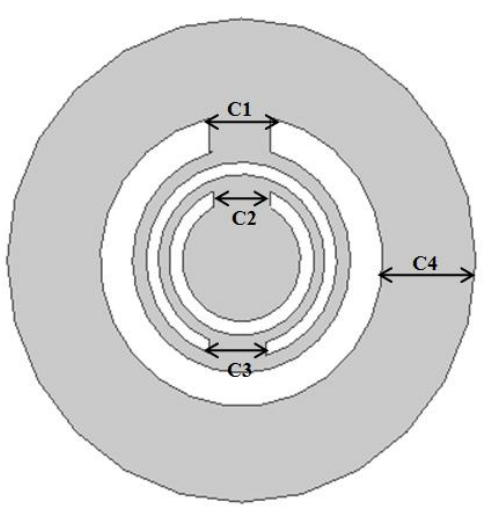

Fig. 1 - CSRR Structure

Table 1 - Dimensions of the AMC unit cell

\begin{tabular}{|c|c|}
\hline Parameters & Dimensions, $\mathrm{mm}$ \\
\hline $\mathrm{W}_{\mathrm{P}}$ & 12.6 \\
\hline $\mathrm{LP}_{\mathrm{P}}$ & 12.6 \\
\hline $\mathrm{C}_{1}$ & 1.5 \\
\hline $\mathrm{C}_{2}$ & 1.4 \\
\hline $\mathrm{C}_{3}$ & $1.4 \mathrm{~mm}$ \\
\hline $\mathrm{C}_{4}$ & $2.32 \mathrm{~mm}$ \\
\hline
\end{tabular}

illustrated in Fig. 2 while the unit cell dimensions plotted in Table 1.

\section{ANTENNA DESIGN}

In Fig. 3, the reflection coefficient attributes of the single component iterations proposed are introduced. It is shown that from 26.8 to $37.8 \mathrm{GHz}$, antenna 4 has better impedance bandwidth. Consequently, the last proposed single part for the CPW Antenna is iteration 4 . The broad band features are given by the simple circular polarised monopole antennas, which are operating in the frequency range of $5.2-15.8 \mathrm{GHz}$ with impedance bandwidth of $3.26 \mathrm{~dB}$ shown in the Fig. 3 . The antenna is further changed with ground and iterations are shown in the Fig. 2. The second iteration gives the return loss of $3.97,2.6$ and $1.3 \mathrm{~dB}$ with the frequency spectrum of 4.9, 9.2 and $13.7 \mathrm{GHz}$ respectively.

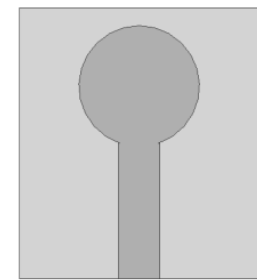

(a)

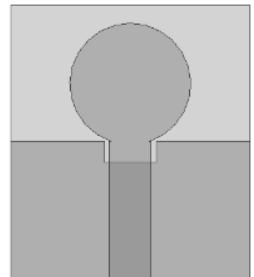

(b)

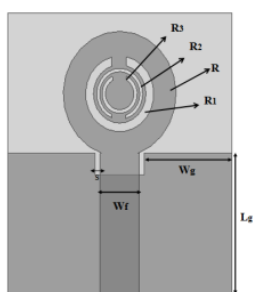

(c)
Fig. 2 - Iterations of the antenna: (a) iteration 1, (b) iteration 2 , (c) iteration 3

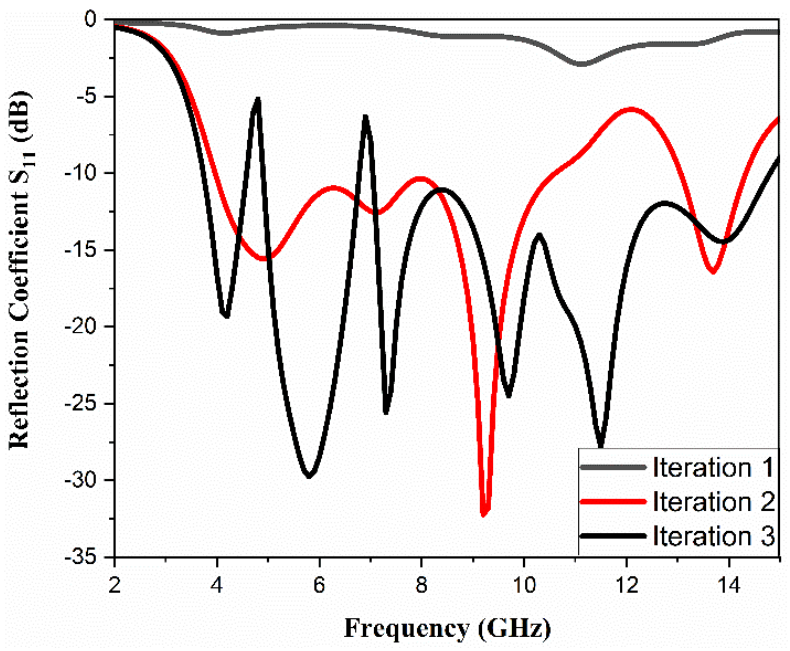

Fig. 3 - Reflection coefficient of the given iterations

Table 2 - Measurements of the Suggested antenna

\begin{tabular}{|c|c|}
\hline Parameters & Dimensions, $\mathrm{mm}$ \\
\hline $\mathrm{W}$ & 23.0 \\
\hline $\mathrm{L}$ & 26.0 \\
\hline $\mathrm{R}$ & 5.8 \\
\hline $\mathrm{R}_{1}$ & 3.5 \\
\hline $\mathrm{R}_{2}$ & 2.7 \\
\hline $\mathrm{R}_{3}$ & 2.06 \\
\hline $\mathrm{L}_{\mathrm{g}}$ & 13.0 \\
\hline $\mathrm{W}_{\mathrm{f}}$ & 4.0 \\
\hline $\mathrm{W}_{\mathrm{g}}$ & 9.0 \\
\hline $\mathrm{S}$ & 0.5 \\
\hline
\end{tabular}


The antenna 3 provides the peak gain values with the frequency of $13.9 \mathrm{GHz}$ by placing of circular CSRR slots in the patch.

Table 3-Comparison of Suggested antenna with existing Literature

\begin{tabular}{|c|c|c|c|c|c|}
\hline Ref. No & $\begin{array}{c}\text { Antenna } \\
\text { Dimension } \\
(\mathrm{mm} \times \mathrm{mm} \times \mathrm{mm})\end{array}$ & $\begin{array}{c}\text { Operating } \\
\text { Frequency, } \\
\mathrm{GHz}\end{array}$ & $\begin{array}{c}\text { Operating } \\
\text { Bands }\end{array}$ & $\begin{array}{c}\text { Imp } \\
\mathrm{B} . \mathrm{W}, \\
\mathrm{GHz}\end{array}$ & $\begin{array}{c}\text { Peak } \\
\text { Gain, } \\
\mathrm{dBi}\end{array}$ \\
\hline 1 & $\begin{array}{c}1.21 \lambda_{0} \times 0.90 \\
\lambda_{0} \times 1.6\end{array}$ & $4.25-5$ & 3 & 2.62 & 4.92 \\
\hline 2 & $32 \times 24 \times 1.6$ & $5-8.4$ & 2 & 6.1 & 4.5 \\
\hline 3 & $60 \times 0 \times 0.8$ & $2.04-7.95$ & 3 & 6 & 4.15 \\
\hline 4 & $\begin{array}{c}R=150, \\
L=45\end{array}$ & $\begin{array}{c}1.575- \\
1.602\end{array}$ & 2 & 2.2 & 9.8 \\
\hline 5 & $60 \times 54 \times 1.52$ & $5.1-8.6$ & 2 & 11.07 & 6 \\
\hline 6 & $13.43 \times 13 \times 0.8$ & $7-10.2$ & 3 & $\begin{array}{c}3.1- \\
17.5\end{array}$ & 5.67 \\
\hline 7 & $27 \times 23$ & $5.2-7.75$ & 3 & 8.1 & 5.1 \\
\hline 8 & $7 \times 3$ & $2.85-8.7$ & 2 & $\begin{array}{c}2.85- \\
8.7\end{array}$ & 6.9 \\
\hline 9 & $100 \times 75 \times 1.6$ & $1-7$ & 2 & 4.9 & 4.6 \\
\hline Proposed & $23 \times 26 \times 1.6$ & $4.2-13.9$ & 3 & 5 & 8.27 \\
\hline
\end{tabular}

\section{OUTCOMES \& DISCUSSION}

The simulation of the Suggestedantenna is done by utilizing HFSS (Ansys) software. Fig. 2 shows the evaluations of the antenna. The $26 \times 23 \times 1.6$ antenna containing of FR4 substrate with the thickness of $1.6 \mathrm{~mm}$. The antenna physical structure is shown in the figure with top view and bottom view whereas the antenna dimensions are illustrated in the Fig. 2. The impedance bandwidth of the antenna is $1.36,2.59 \mathrm{dBi}$ at $4.2 \mathrm{GHz}$ and $5.5 \mathrm{GHz}$ frequency. At $7.6 \mathrm{GHz}$ and $9.7 \mathrm{G} \mathrm{Hz}$ the bandwidth is 1.14 and 2.26 with the wideband. The proposed antenna is operates at various frequencies listed as $4.2 \mathrm{GHz}, 5.5 \mathrm{GHz}, 7.6 \mathrm{GHz}, 9.7 \mathrm{GHz}, 11.4 \mathrm{GHz}$ and $13.9 \mathrm{GHz}$. Table 2 gives the dimensions of the suggested prototype whereas the previous literature comparison is described in the Table 3. The parameters i.e., Antenna size, impedance bandwidth, Operating frequency and Peak gain comparison was discussed.

\subsection{Parametric Analysis}

To achieve the optimized boundaries of the suggested design the parameter examination is done. The effects of circular patch parametric are shown in the Fig. 4(c) it shows that the sweep of the circle is changed from 2.5 to $4.5 \mathrm{~mm}$ with the step size of $1 \mathrm{~mm}$. The Ground plane parametric effects are observed in the Fig. 4(b) with the magnitude parameters $\left(\mathbf{S}_{11}\right)$ are varying from 12 to $14 \mathrm{~mm}$. In figure 4(a) the parametric analysis of width of the feed is discussed by changing the values from $3 \mathrm{~mm}$ to $6 \mathrm{~mm}$ by step size of $0.5 \mathrm{~mm}$.

\subsection{Polar Plots}

The 3Dpolar characteristics of the suggested antenna are illustrated in the figure 5. So as to gauge the capacity in a specific direction, the radio energy of the antenna, the gain of the antenna gives the arrangement. From Fig.5a, the peak gain of 8.27 is observed at $13.9 \mathrm{GHz}$ Frequency radiation is occurred in around the axis. The radiation is subjected to $\mathrm{y}$ and $\mathrm{z}$ axis with the

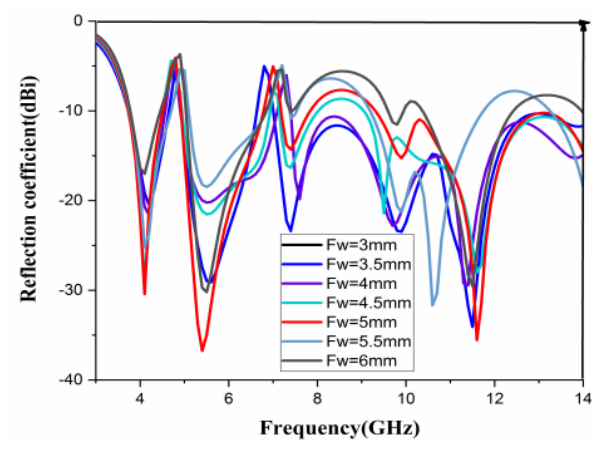

(a)

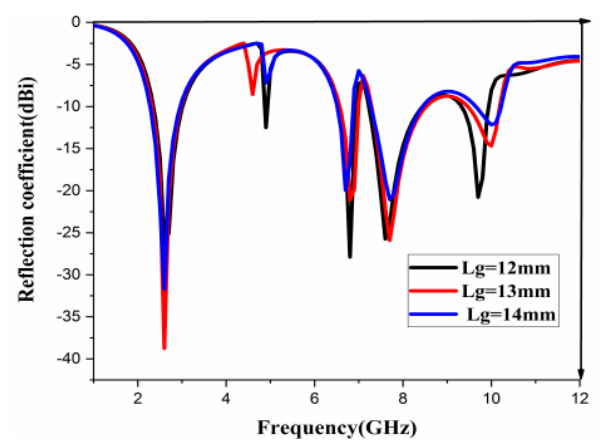

(b)

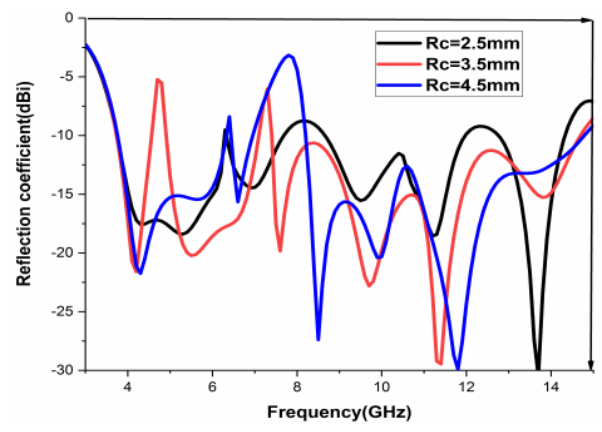

(c)

Fig. 4 - Reflection coefficient $\left(\mathrm{S}_{11}\right)$ of the antenna: (a) feed parametric, (b) ground parametric, (c) circle parametric

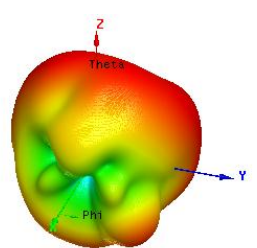

(a)

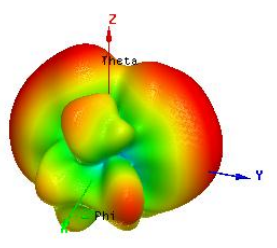

(b)

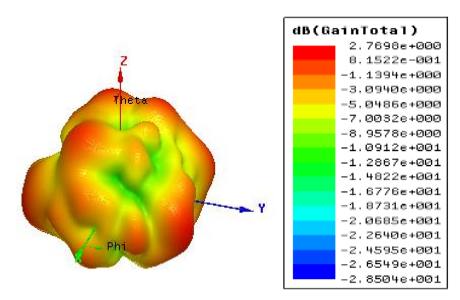

(c)

Fig. 5 - 3D Polar Plots of the Advised Antenna: (a) @9.7 GHz, (b) @11.4 GHz and (c) @13.9 GHz 
peak gain of $2.76 \mathrm{~dB}$ at $4.2 \mathrm{GHz}$. At $5.5 \mathrm{GHz}, 7.6 \mathrm{GHz}$ and $9.7 \mathrm{GHz}$ the Peak gain of $3.83,2.98$ and $4.53 \mathrm{~dB}$ respectively with the radiation is formed throughout the axis. The radiation is presented in the $\mathrm{Y}$ and $\mathrm{Z}$ directions at $11.4 \mathrm{GHz}$ with the peak gain of $8.27 \mathrm{dBi}$ respectively.

\subsection{Radiation Patterns}

The Simulated Radiation characteristics of the proposed antenna are described. Furthermore, it is seen that the Simulated radiation qualities of $\mathrm{YZ}$ plane $(\varphi=90)$, ZX plane $(\varphi=0) \& X Y$ plane $(\varphi=90)$ are shown in the Fig. 6 . In XY PLANE Butterfly shape radiation patterns are delivered at all frequencies. YZ PLANE consisting of Dipole shape radiation patterns, at 11.4 and $13.9 \mathrm{GHz}$ frequencies we can observe OMNI directional radiation patterns. In ZX PLANE bidirectional radiation patterns are occurred.

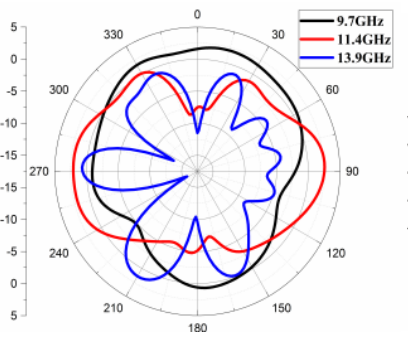

(a)

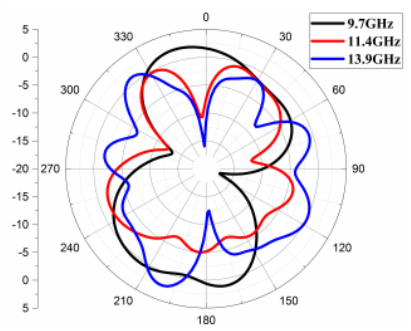

(b)

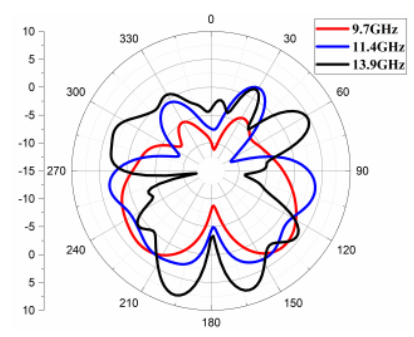

(c)

Fig. 6 - Simulated radiation characteristics of the antenna: (a) YZ Plane (b) ZX Plane (c) XY Plane

\subsection{Return Loss}

The Simulated and Measured Reflection coefficient results are discussed in Fig. 7. The practical measured results are derived by ROHDE \&and SCHWARZ Vector Network Analyzer. The measured results seem to be good agreement to the simulated return loss. The radiation qualities of the antenna in the working band and in the notch, band is introduced.

\subsection{Surface Current Distributions}

At different frequencies, current distributions on the surface of the suggested prototype are illustrated in figure 8 . At $4.2 \mathrm{GHz}$ current distribution is formed in the patch and some part of the feed. The surface current is resonated within the feed at $5.5 \mathrm{GHz}$. The distributed current is occurred in the feed with the frequency of $7.6 \mathrm{GHz} .9 .7 \mathrm{GHz}$ current distributed in feed and some parts of the ground. The magnitude of the current from the simulated observations is generated in the feed and CSRR with the resonating frequency of $11.4 \mathrm{GHz}$. At $13.9 \mathrm{GHz}$ surface current is distributed throughout the antenna i.e., Patch, Feed and ground.

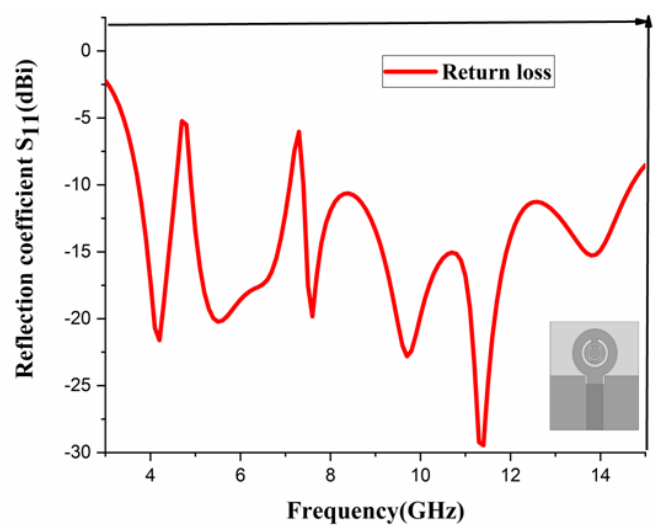

(a)

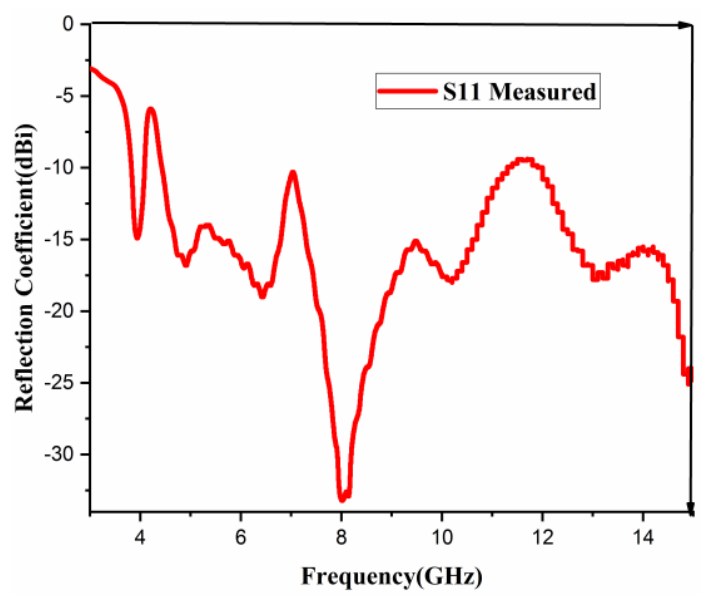

(b)

Fig. 7 - Return loss characteristicsof the suggested antenna: (a) simulated and (b) measured

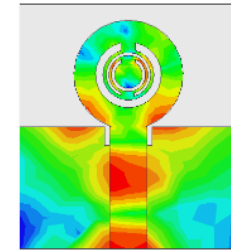

(a)

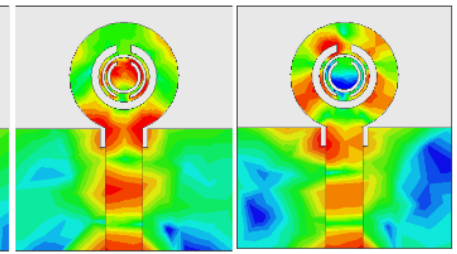

(b) (c)
Fig. 8 - Surface current distributions at various frequencies: (a) $9.7 \mathrm{GHz}$, (b) $11.4 \mathrm{GHz}$ and (c) $13.9 \mathrm{GHz}$

The Simulated and Measured Results are described by using the Rohde ans Schwarz ZNB Vector Network Analyzer. The measured results seem to be very closer to the simulated results.

\section{CONCLUSIONS}

A circular patch monopole microstrip patch antenna with CSRR slots has been introduced practically. Wide impedance is achieved by placing of CSRR. The distribution of surface currents at the indented frequencies 
with the placement of resonator and without placement of resonators are also processed and examined. Simulated results of the circular patch antenna are presented, such as coefficient of magnitude reflection, VSWR, Gain, Radiation quality, 3D-simulation of polar plots. The suggested broadband Circular Patch antenna is ease, simply planned. Consequently, making it a rea-

\section{REFERENCES}

1. B.R. Behera, P. Srikanth, P.R. Meher, SK. Mishra, AEU Int. J. Electron. Communic. 120, 153233 (2020).

2. D. Yadav, M.P. Abegaonkar, S.K. Koul, V. Tiwari, D. Bhatnagar, AEU-Int. J. Electron. Communic. 84, 313 (2018).

3. U. Banerjee, A. Karmakar, A. Saha, P. Chakraborty, AEU-Int. J. Electron. Communic. 110, 152831 (2019).

4. S.C. Yadav, S.P. Duttagupta, N. Atmakuru, AEU-Int. J. Electron. Communic. 106, 48 (2019).

5. A. Altaf, M. Seo, IEEE Antennas Wirel. Propag. Lett. 17 No 12, 2464 (2018).

6. P. Chaudhary, A. Kumar, AEU-Int. J. Electron. Communic. 107, 137 (2019).

7. M.A. Salamin, S. Das, A. Zugari, AEU-Int. J. Electron. Communic. 97, 45 (2018).

8. B. Mohamadzade, R.B. Simorangkir, R.M. Hashmi, K.P. Esselle, IEEE Int. Workshop Antenna Technol. (iWAT), 1 (2020).

9. B.R. Behera, P.R. Meher, S.K. Mishra, IEEE 6th International Conference on Signal Processing and Integrated Networks (SPIN), 1147 (2019).

10. R. Dhara, S.K. Jana, M.M. Sharma, I.B. Sharma, IEEE Indian Conference on Antennas and Propogation (InCAP), 1 (2019).

11. Q. Guo, J. Zhang, Y. Wang, C. Song, IEEE Computing, sonable application for Wi-MAX and satellite communication operations.

\section{ACKNOWLEDGMENTS}

The authors would like to thank the KLEF (deemed to be university) and Department of ECE.

Communications and IoT Applications (ComComAp), 361 (2019).

12. D.K. Singh, B.K Kanaujia, S. Dwari, G.P. Pandey, AEUInt. J. Electron. Communic. 95, 177 (2018).

13. H. Alsariera, Z. Zakaria, A.B.A.M. Isa, AEU-Int. J. Electron. Communic. 118, 153139 (2020).

14. P. Sehgal, K. Patel, IEEE 7th International Conference on Signal Processing and Integrated Networks (SPIN), 1078 (2020).

15. Y. Seo, J. Jung, H. Lee, Y. Lim, Microwave Opt. Technol. Lett. 54 No 7, 1549 (2012).

16. Q. Wu, R. Jin, J. Geng, Microwave Opt. Technol. Lett. 50 No 5, 1285 (2008)

17. S.S.S. Kalyan, K.C.S. Kavya, S.K. Kotamraju, J. Adv. Res. Dyn. Control. Syst., 63 (2017).

18. B.T.P. Madhav, M. Sanikommu, M.N.V.S. Pranoop, K.S.N.M.C. Bose, B.S. Kumar, Indian J. Sci. Technol. No S9, 119 (2015).

19. A. Alwis, Study on the potential for biogas in Sri Lanka (ITDG South Asia: 2001).

20. G. Tilak, S.K. Kotamraju, B.T. Madhav, K. Kavya, M.V. Rao, J. Eng. Sci. Technol. 15 No 3, 1952 (2020).

21. G.B. Tilak, S.K. Kotamraju, B.T. Madhav, K.C. Kavya, M.V. Rao, J. Electrical Eng. 71 No 5, 298 (2020). 